\title{
Effects of conjugated linoleic acid on the performance of laying hens, lipid composition of egg yolk, egg flavor, and serum components
}

\author{
Xuelan Liu ${ }^{1, *}$, Yan Zhang ${ }^{1}$, Peipei Yan', Tianhong Shi ${ }^{1}$, and Xiangfa Wei ${ }^{1}$
}

* Corresponding Author: Xuelan Liu Tel: +86-0531-85965657, Fax: +86-0531-85999436,

E-mail: liuxuelan7411@sina.com

'Poultry Research Institute, Shandong Academy of Agricultural Sciences, Jinan 250023, China

Submitted Dec 17, 2015; Revised Jan 27, 2016; Accepted Jun 2, 2016
Objective: This experiment investigated the effects of dietary supplementation with conjugated linoleic acid (CLA) on the serum components, laying hen productivity, lipid composition of egg yolk, egg flavor and egg quality.

Methods: Healthy 28-week-old Hy-Line white laying hens $(\mathrm{n}=480)$ were divided randomly into 4 groups, 6 replicates/group, 20 birds/replicate. The 30-day experimental diets included $0 \%$ (control), $0.4 \%, 0.8 \%$, and $1.6 \%$ CLA. Some serum indices of the birds, and egg production, quality, fatty acid composition, egg quality were measured.

Results: The dietary supplementation with $0.4 \%, 0.8 \%$, and $1.6 \%$ CLA did not significantly affect the laying rate and feed intake, as well as calcium ion and phosphorus ion concentration in serum ( $p>0.05)$. However, the CLA had significantly increased the strength of eggshell, decreased the odor, flavor, and taste of egg yolk, deepened the color of egg yolk, increased saturated fatty acids and polyunsaturated fatty acids, and reduced the monounsaturated fatty acids $(\mathrm{p}<0.05)$. On the other hand, the dietary supplementation with $1.6 \%$ CLA had significant effects on feed/gain, and improved serum hormones. Dietary supplementation with $0.4 \%$ and $0.8 \%$ CLA can significantly enhance the activity of alkaline phosphates.

Conclusion: CLA has no effect on production performance, but does enhance the lipid content of the egg yolk and the strength of the eggshell.

Keywords: Laying Hen; Dietary Supplementation; Conjugated Linoleic Acid; Feed Efficiency; Lipid Composition

\section{INTRODUCTION}

In China, people's living standards have greatly improved with the rapid development of the economy, and the people's diets have changed accordingly. In recent years, the increased consumption of high-fat and high-cholesterol foods such as meat and eggs has resulted in higher incidences of cardiovascular disease, including in young people [1]. This has become a major public health problem. Cardiovascular diseases not only seriously harm people's health, but also consume a large amount of medical resources, according to estimates of the World Health Organization[2]. If no effective measures are taken, this situation will cause huge economic losses for China in the next 10 years [2]. Medicinal drugs and alterations in life style are effective ways to control these diseases. However, the long-term use of drugs carries risks of adverse side effects, and it is difficult to change the eating habits of a large population.

A relatively new concept in disease prevention is the consumption of functional foods, that is, foods with added nutritional or health-promoting benefits. The potential additive considered here is conjugated linoleic acid (CLA), discovered in the 1980s [3]. Since its discovery, investigations have shown that CLA may benefit immune modulation, weight reduction, and prevention of diseases such as cancer and arteriosclerosis [4-6]. Thus, CLA has attracted wide attention 
in the fields of medicine, food science, and nutrition.

In animal nutrition, a main goal is to produce livestock and poultry products that contain CLA, while maintaining flavor and other desirable food qualities. Thus, people can enjoy the food while preventing cardiovascular disease. Research has proved that CLA can be enriched in meat [7] and eggs [8,9]. For the meat industry, CLA has been shown to enhance the immunity of animals $[10,11]$, reduce the carcass fat content of pigs [12-14], and improve the quality of meat [14,15]. However, the effect of CLA on the egg production performance and egg quality of laying hens is controversial.

Jones et al [9] reported that the rate of egg production was significantly decreased by CLA in hens' diets, even at levels as low as $0.5 \%$ to $1.0 \%$. Moreover, in most studies with poultry, CLA supplementation led to reduced feed intake $[8,16]$, although Reas [17] showed that CLA did not change feed intake at levels of $1.0 \%$. Shang et al [18] found that dietary CLA negatively correlated with feed consumption, body weight gain, rate of egg production, egg weight, and feed/gain. However, Cherian et al [19] reported that CLA-supplementation did not affect feed consumption, daily egg production, feed efficiency, or egg weight. Another study reported a 7\% reduction in egg production, but no reduction in egg or yolk weight, after a 68-wk-long trial in which CLA was included at 0.5 and $1.0 \mathrm{~g} / \mathrm{kg}$ in the hens' diet [9]. Yet, Schafer et al [20] reported that feeding $29 \mathrm{~g}$ CLA $/ \mathrm{kg}$ for $80 \mathrm{wk}$ did not affect egg production or egg weight, and another investigation found that the performance of laying hens was not affected by dietary CLA concentration [21].

Regarding egg quality for the consumer, Ahn et al [16] reported that dietary CLA increased the firmness of hard-cooked egg yolk, making the yolks rubbery and elastic, which may reduce their acceptability. Shang et al [18] reported that the addition of CLA to more than $4 \%$ of diets had a negative effect on egg yolk flavor, but when the amount was less than $3 \%$, no adverse effect was observed.

In an attempt to resolve these controversies, we investigated the effects of dietary CLA on performance, egg quality, and serum components of laying hens. The findings are expected to benefit the successful development of CLA-enriched eggs.

\section{MATERIALS AND METHODS}

\section{Birds, diets, housing, and sampling}

Four hundred and eighty Hy-line white hens at 28 weeks of age were included in the study. Hens were randomly divided into 4 groups of 480 birds. Each group was further randomly divided into 6 replicates of 20 hens.

In each replicate, hens were housed in wire-floored metal cages ( $40 \mathrm{~cm}$ wide $\times 45 \mathrm{~cm}$ long $\times 45 \mathrm{~cm}$ high), 4 hens per cage. Hens were provided with food and water ad libitum during the 30-d experimental period. The photoperiod was set at 17 $\mathrm{h}$ light-to-7 $\mathrm{h}$ dark. The room temperature was maintained at $25^{\circ} \mathrm{C} \pm 5^{\circ} \mathrm{C}$.

Four corn-soybean meal-based diets were formulated using $0 \%, 0.5 \%, 1 \%$, or $2 \%(\mathrm{w} / \mathrm{w})$ of a lipid product that contains $80 \%$ CLA (Aohai, Qingdao, Shangdong Province, China), resulting in diets containing $0 \%, 0.4 \%, 0.8 \%$, and $1.6 \%$ CLA, respectively (Table 1). Soybean oil was used $(1.6 \%, 1.2 \%, 0.8 \%$, and $0 \% \mathrm{w} / \mathrm{w}$, respectively, of the total diet) to supplement the amount of CLA used, to equalize the energy intake in the diets. To avoid fat oxidation, diets were freshly prepared each week, and 0.04 $\mathrm{kg} / 1,000 \mathrm{~kg}$ of an antioxidant $(0.02 \%$ ethoxyquin, Shanghai San Wei Feed Additive, Beijing, China) was added to all diets. The diets were formulated to provide 2,700 kcal metabolisable energy/ $\mathrm{kg}, 0.98 \%$ total lysine, $0.47 \%$ total methionine, $3.52 \%$ calcium, and $0.61 \%$ total phosphorus. The addition of vitamins and trace elements conformed to the provisions of the 1,224 announcement by the Ministry of Agriculture of China (2009).

Egg production and egg weight were recorded daily, and feed consumed was recorded weekly for 30 days. Average feed efficiency was calculated. Four eggs from each replicate for each treatment were used to measure the quality of the main egg components (shell, yolk, and albumen) on day 27. Yolk color was determined by comparing yolk color to the Roche color fan.

On day 30, 12 hens ( 2 birds per replicate) were randomly selected from each group to collect peripheral blood from the wing vein. Serum was separated after blood coagulation, and stored at $-20^{\circ} \mathrm{C}$ for subsequent analysis.

At days $7,14,21$, and 28 , four eggs were randomly selected from each replicate (24 eggs per treatment) and separated into yolk and albumen to analyze the fatty acid composition. Chamruspollert and Sell (1999) reported that the maximum level of CLA in egg yolk lipids appears from 10 to $11 \mathrm{~d}$ after CLA feeding is initiated. Therefore, using the ISO standard 5492 (2010) for

Table 1. Feed ingredients of experimental diets

\begin{tabular}{|c|c|c|c|c|}
\hline & \multicolumn{4}{|c|}{ Percent dietary CLA } \\
\hline & 0 & 0.4 & 0.8 & 1.6 \\
\hline Corn & 58 & 58 & 58 & 58 \\
\hline Wheat bran & 3 & 3 & 3 & 3 \\
\hline Soybean meal & 18 & 18 & 18 & 18 \\
\hline Cottonseed meal & 6 & 6 & 6 & 6 \\
\hline Soybean oil & 2 & 1.5 & 1 & 0 \\
\hline $\operatorname{CLA}(80 \%)^{1)}$ & 0 & 0.5 & 1 & 2 \\
\hline Limestone & 8 & 8 & 8 & 8 \\
\hline Premix ${ }^{2)}$ & 5 & 5 & 5 & 5 \\
\hline Total & 100 & 100 & 100 & 100 \\
\hline
\end{tabular}

CLA, conjugated linoleic acid.

1) Containing $39.70 \%$ of the cis- 9 , trans- 11 isomer, and $41.21 \%$ of the trans- 10 , cis-12 isomer.

2) Premix supplies per kilogram of diet: protein, $280 \mathrm{~g}$; Met, $28 \mathrm{~g}$; dicalcium phosphate, $160 \mathrm{~g}$; vitamin $\mathrm{A}, 160,000 \mathrm{IU}$; vitamin $\mathrm{D}_{3}, 32,000 \mathrm{IU}$; vitamin $\mathrm{E}, 400 \mathrm{IU}$; vitamin $\mathrm{K}_{3}, 20 \mathrm{mg}$; vitamin $\mathrm{B}_{1}, 110 \mathrm{mg}$; vitamin $\mathrm{B}_{2}, 100 \mathrm{mg}$; vitamin $\mathrm{B}_{6}, 160 \mathrm{mg}$; vitamin $\mathrm{B}_{12}, 1.6$ $\mathrm{mg}$; niacin, $320 \mathrm{mg}$; biotin, $6 \mathrm{mg}$; D-pantothenic acid, 1,800 mg; folic acid, $300 \mathrm{mg}$; choline chloride, 30,000 mg; copper, $160 \mathrm{mg}$; iron, 1,400 mg; manganese, 1,200 mg; zinc, $1,600 \mathrm{mg}$. 
sensory analysis, ten eggs were randomly selected in each treatment to assess the sensory indexes of egg yolk at $11 \mathrm{~d}$.

\section{Laboratory analysis}

The fatty acid composition of egg yolk was analyzed in accordance with the method described by Raes et al [17]. Heptadecaenoic acid (17:0) was used as an internal standard. Fatty acid methyl esters were analyzed by gas chromatography on an HP6890 GC system (Hewlett-Packard, Wilmington, DE, USA) installed with a Chrompack capillary column (CP-Sil 88 column, 100 $\mathrm{m} \times 250 \mu \mathrm{m} \times 0.25 \mu \mathrm{m}$, Varian, Palo Alto, CA, USA). The chromatography conditions were as follows: injector temperature at $250^{\circ} \mathrm{C}$; detector temperature at $250^{\circ} \mathrm{C}$; helium as the carrier gas, split ratio 1:40; temperature program set to $180^{\circ} \mathrm{C}$ for 45 min, followed by an increase of $10^{\circ} \mathrm{C} / \mathrm{min}$ to $215^{\circ} \mathrm{C}$, and then maintained for $17 \mathrm{~min}$. Peaks were identified compared to the retention times of the corresponding standards (Sigma, St. Louis, MO, USA; Matreya Biochemicals, State College, PA, USA). The peaks identified included fatty acids between 14:0 and 24:1 and 6 different CLA isomers. The trans-8, cis-10 CLA isomer was probably present in the CLA product, but its peak overlapped with that of cis-9, trans-11 CLA and it could not be differentiated. The determination was carried out at the China Ministry of Agriculture Feed Industry Center.

Egg quality was measured using an egg quality analyzer (EMT5200 Robotmation, Japan). Calcium $\left(\mathrm{Ca}^{2+}\right)$ was measured by the methylthymol blue colorimetric method; phosphorous $\left(\mathrm{P}^{5+}\right)$ was determined by the ultraviolet endpoint assay. The activity of alkaline phosphatase was assayed by a microtiter assay (with para-nitrophenyl phosphate as the substrate). All indexes were measured using assay kits (Beijing Lidman Biological Technology, China) in accordance with manufacturer's instructions.

The hormone content of sera was measured using a chemiluminescent immunoassay at General Hospital of Jinan Area Military.

For evaluation of the sensory indexes, 12 eggs were taken from each treatment, stored at room temperature for 7 days, boiled in water for 15 minutes, and evaluated by a panel of experts from the Food Science College at Jinan University. The color, smell, taste, and mouth feeling of the egg yolks were scored in accordance with the standard of sensory evaluation of egg yolk (Table 2).
Table 2. Standards of yolk sensory evaluation ${ }^{1)}$

\begin{tabular}{llcc}
\hline \multicolumn{1}{c}{ Standard of sensory evaluation } & $\begin{array}{c}\text { Deducted } \\
\text { scores }\end{array}$ & Scores \\
\hline Color & More yellow than ordinary color & 0 & 10 \\
& Normal color & 1 & 9 \\
& Canary yellow & 2 & 8 \\
& Slight yellow & 3 & 7 \\
& White & 4 & 6 \\
Odor $\quad$ Better than the normal flavor & 0 & 20 \\
& Normal taste, no peculiar smell & 2 & 18 \\
& A little peculiar smell & 4 & 16 \\
& Peculiar smell, but tolerable & 6 & 14 \\
& Strong peculiar smell, difficult to accept & $7-10$ & $13-10$ \\
Flavor $\quad$ Better taste than normal yolk & 0 & 40 \\
& Normal flavor & 3 & 37 \\
& Normal flavor with a little peculiar smell & 5 & 35 \\
& Peculiar smell, but tolerable & $6-12$ & $34-28$ \\
& Very obvious smell, difficult to accept & $13-20$ & $27-20$ \\
Taste $\quad$ Better than normal yolk & 0 & 30 \\
& Special taste of normal yolk & $2-3$ & $28-27$ \\
& Special taste of normal yolk, but slightly hard & $4-6$ & $26-24$ \\
& Taste uncomfortable, but acceptable & $7-10$ & $23-20$ \\
& Taste very uncomfortable, difficult to accept & $10-15$ & $20-15$ \\
\hline
\end{tabular}

${ }^{1)}$ Maximum scores: color, 10; odor, 20; flavor, 40; taste, 30.

\section{Statistical analyses}

All data are presented as mean \pm standard error of the mean, and analyzed using ANOVA analysis of variance with the statistical software SPSS 11.0 (SPSS, Chicago, IL, USA), followed by the Duncan multiple range test. Less than $0.05 \mathrm{p}$ value was considered a significant difference. The effects of increasing CLA were partitioned into linear and quadratic components using polynomial contrasts

\section{RESULTS}

\section{Production performance}

Average daily feed intakes were similar in all treatment groups, while hens fed the 1.6\% CLA diet tended to consume slightly less feed than other hens (Table 3 ). Hens fed the $0.4 \%, 0.8 \%$, and $1.6 \%$ CLA diets produced more eggs than the hens fed with the control diet (0\% CLA), although the differences in all treatment groups were not significant .However, dietary supplementation with 1.6\% CLA had significant effects on feed conversion ( $\mathrm{p}<0.05$;

Table 3. Effects of CLA on performance of laying hens

\begin{tabular}{|c|c|c|c|c|c|c|}
\hline & \multicolumn{4}{|c|}{ Percent dietary CLA } & \multicolumn{2}{|c|}{$\mathrm{p}$-value } \\
\hline & 0 & 0.4 & 0.8 & 1.6 & Linear & Quadratic \\
\hline Feed/gain ${ }^{1)}(\mathrm{kg}: \mathrm{kg})$ & $2.27 \pm 0.03^{b}$ & $2.25 \pm 0.01^{b}$ & $2.24 \pm 0.02^{b}$ & $2.36 \pm 0.01^{\mathrm{a}}$ & 0.001 & 0.001 \\
\hline Laying rate (\%) & $90.30 \pm 0.65^{a}$ & $91.74 \pm 1.35^{\mathrm{a}}$ & $94.20 \pm 1.14^{\mathrm{a}}$ & $91.07 \pm 1.23^{\mathrm{a}}$ & 0.421 & 0.003 \\
\hline Feed consumption (g/hen/d) & $124.0 \pm 3.17^{\mathrm{a}}$ & $124.5 \pm 2.88^{\mathrm{a}}$ & $124.9 \pm 4.53^{\mathrm{a}}$ & $123.0 \pm 2.27^{\mathrm{a}}$ & 0.683 & 0.567 \\
\hline
\end{tabular}

CLA, conjugated linoleic acid.

${ }^{1)}$ The feed/gain was increased linearly and quadraticlly.

a,b Values with no common superscript differ significantly $(p<0.05)$ respectively when tested with Duncan's multiple range test. 
Table 3).

\section{Egg quality}

Dietary supplementation with CLA, at all concentrations, was associated with significantly stronger eggshells $(\mathrm{p}<0.05$; Table 4). Eggshell thickness, the Haugh unit, and egg weight were similar among the different treatment groups (Table 4).

\section{Sensory parameters of egg yolk}

Increasing CLA concentrations were associated with significant reductions in consumer desirability of egg yolks, in terms of odor, flavor, and taste $(\mathrm{p}<0.05$, all; Table 5$)$, and deepening of egg yolk color $(\mathrm{p}<0.05)$.

\section{Fatty acid profile of egg yolk}

CLA supplementation was associated with significantly higher total saturated fatty acid (SFA) and polyunsaturated fatty acid (PUFA) contents compared with the control group $(\mathrm{p}<0.05)$, and significantly lower monounsaturated fatty acids (MUFAs; $\mathrm{p}<0.05$; Table 6).

Compared with the control group, almost all the SFAs in yolk were significantly altered in the groups given dietary CLA, except for lignin acid. Hens fed 1.6\% CLA had significantly higher lauric acid, myristic acid, palmitic acid, heptadecanoic acid, stearic acid, and arachidic acid in egg yolk compared with the controls, while the content of behenic acid content was significantly less.

Except for eicosapentaenoic acid, all the MUFAs in egg yolk were altered with increasing dietary CLA supplementation, relative to the controls; the contents of octadecadienoic acid and eicosadienoic acid were significantly higher, while that of linolenic acid, arachidonic acid, docosatetraenoate, docosapentenoic acid, and docosahexaenoic acid were significantly lower $(\mathrm{p}<0.05$, all).
The total amounts of CLA transferred into egg yolk lipids correlated significantly and positively with dietary CLA $(\mathrm{p}<0.05)$.

\section{Hen serum components}

Increases in dietary CLA were associated with tendencies toward increases in triothyrone, tetraiodothyronine, cortisol, and estradiol (Table 7). The levels of serum hormones were significantly higher in hens fed diets containing 1.6\% CLA than in the other hens $(p<0.05)$. Analysis showed that CLA was associated with significantly enhanced alkaline phosphatase enzyme activity $(\mathrm{p}<0.05)$; the concentrations of calcium and phosphorus ions tended to increase although not significantly.

\section{DISCUSSION}

\section{Production performance}

It has been reported that reductions in feed intake, egg production, egg weight, and feed conversion are associated with increasing CLA concentrations in diets $[8,16,18,22]$. Our study showed that the laying rate of hens fed with diets containing CLA was higher than that of the controls, while the average daily feed intake remained similar among all treatments. When hens were fed diets containing $0.4 \%$ or $0.8 \%$ CLA, their egg-laying and feed conversion rates were higher than those of the control group. However, in hens fed 1.6\% CLA, these rates were lower than the control group. These results consistent with that of previous works [18]. Estrogen has been shown to promote follicular growth, while cortisol reduces egg production [23]. In this study, when the proportion of dietary CLA was $0.4 \%$ or $0.8 \%$, the levels of serum thyroid hormone and estradiol were higher than that of the control group, resulting in better production performance as compared to hens without CLA supplementation [24,25].

Table 4. Effects of CLA on egg quality of laying hens

\begin{tabular}{|c|c|c|c|c|c|c|}
\hline & \multicolumn{4}{|c|}{ Percent dietary CLA } & \multicolumn{2}{|c|}{$\mathrm{p}$-value } \\
\hline & 0 & 0.4 & 0.8 & 1.6 & Linear & Quadratic \\
\hline Eggshell strength $\left(\mathrm{kg} / \mathrm{cm}^{2}\right)$ & $3.70 \pm 0.72^{b}$ & $4.30 \pm 0.95^{\mathrm{a}}$ & $4.89 \pm 0.92^{\mathrm{a}}$ & $4.70 \pm 0.55^{\mathrm{a}}$ & 0.164 & 0.263 \\
\hline Eggshell thickness (mm) & $0.33 \pm 0.02$ & $0.36 \pm 0.04$ & $0.36 \pm 0.06$ & $0.34 \pm 0.02$ & 0.5 & 0.768 \\
\hline Haugh unit & $81.83 \pm 3.30$ & $80.90 \pm 6.75$ & $81.15 \pm 4.68$ & $81.03 \pm 5.98$ & 0.893 & 0.896 \\
\hline Egg weight (g) & $63.24 \pm 4.67$ & $64.69 \pm 3.42$ & $63.36 \pm 1.67$ & $61.64 \pm 3.35$ & 0.452 & 0.567 \\
\hline
\end{tabular}

CLA, conjugated linoleic acid.

a,b Values with no common superscript differ significantly $(p<0.05)$ respectively when tested with Duncan's multiple range test.

Table 5. Effects of CLA on sensory parameters of egg yolk

\begin{tabular}{|c|c|c|c|c|c|c|}
\hline & \multicolumn{4}{|c|}{ Percent dietary CLA } & \multicolumn{2}{|c|}{$p$-value } \\
\hline & 0 & 0.4 & 0.8 & 1.6 & Linear & Quadratic \\
\hline Yolk color & $6.48 \pm 1.16^{b}$ & $6.26 \pm 1.10^{b}$ & $6.90 \pm 0.94^{b}$ & $7.61 \pm 1.37^{\mathrm{a}}$ & 0.191 & 0.711 \\
\hline Odor & $18.57 \pm 1.86^{b}$ & $17.28 \pm 1.69^{a, b}$ & $16.28 \pm 2.01^{\mathrm{a}}$ & $15.30 \pm 1.97^{\mathrm{a}}$ & 0.059 & 0.618 \\
\hline Flavor & $36.71 \pm 3.03^{b}$ & $32.00 \pm 4.11^{\mathrm{a}}$ & $31.43 \pm 3.56^{a}$ & $31.00 \pm 3.23^{\mathrm{a}}$ & 0.114 & 0.231 \\
\hline Taste & $27.14 \pm 2.21^{b}$ & $26.21 \pm 2.54^{b}$ & $24.11 \pm 3.02^{a}$ & $23.05 \pm 1.99^{\mathrm{a}}$ & 0.059 & 0.683 \\
\hline
\end{tabular}

CLA, conjugated linoleic acid.

a,b Values with no common superscript differ significantly $(p<0.05)$ respectively when tested with Duncan's multiple range test. 
Table 6. Fatty acid composition of egg yolk ${ }^{11}$

\begin{tabular}{|c|c|c|c|c|c|c|c|}
\hline \multirow{2}{*}{ Fatty acid (\%) } & \multirow{2}{*}{ Lipid no. } & \multicolumn{4}{|c|}{ Percent dietary CLA } & \multicolumn{2}{|c|}{$p$-value } \\
\hline & & 0 & 0.4 & 0.8 & 1.6 & Linear & Quadratic \\
\hline Lauric acid & $\mathrm{C} 12: 0$ & $0.01 \pm 0.01^{b}$ & $0.01 \pm 0.01^{b}$ & $0.04 \pm 0.01^{\mathrm{a}}$ & $0.04 \pm 0.01^{\mathrm{a}}$ & 0.00 & 0.114 \\
\hline Myristic acid & C14:0 & $0.33 \pm 0.08^{b}$ & $0.37 \pm 0.05^{b}$ & $0.37 \pm 0.04^{b}$ & $0.41 \pm 0.04^{\mathrm{a}}$ & 0.127 & 0.844 \\
\hline Palmitic acid & C16:0 & $15.55 \pm 1.06^{b}$ & $15.81 \pm 1.50^{b}$ & $17.24 \pm 1.39^{\mathrm{a}}$ & $18.04 \pm 0.97^{\mathrm{a}}$ & 0.026 & 0.820 \\
\hline Heptadecanoic acid & C17:0 & $0.12 \pm 0.01^{b}$ & $0.15 \pm 0.02^{\mathrm{a}, \mathrm{b}}$ & $0.18 \pm 0.02^{\mathrm{a}}$ & $0.19 \pm 0.01^{\mathrm{a}}$ & 0.001 & 0.058 \\
\hline Stearic acid & C18:0 & $5.73 \pm 1.59^{b}$ & $8.00 \pm 0.05^{a}$ & $9.75 \pm 0.61^{\mathrm{a}}$ & $10.32 \pm 1.24^{\mathrm{a}}$ & 0.001 & 0.042 \\
\hline Eicosanoic acid & $\mathrm{C} 20: 0$ & $0.02 \pm 0.01^{b}$ & $0.02 \pm 0.00^{b}$ & $0.06 \pm 0.00^{\mathrm{a}}$ & $0.09 \pm 0.01^{\mathrm{a}}$ & 0.000 & 0.570 \\
\hline Docosanoic acid & $C 22: 0$ & $0.03 \pm 0.01^{\mathrm{a}}$ & $0.03 \pm 0.00^{\mathrm{a}}$ & $0.02 \pm 0.00^{b}$ & $0.02 \pm 0.00^{b}$ & 0.019 & 0.427 \\
\hline Lignin acid & C24:0 & $0.02 \pm 0.00$ & $0.02 \pm 0.00$ & $0.02 \pm 0.00$ & $0.02 \pm 0.00$ & - & - \\
\hline SFA & - & $21.80 \pm 2.73^{b}$ & $24.32 \pm 2.87^{b}$ & $27.67 \pm 3.01^{\mathrm{a}}$ & $29.10 \pm 1.98^{\mathrm{a}}$ & 0.008 & 0.315 \\
\hline Myristoleic acid & C14:1 & $0.06 \pm 0.02^{\mathrm{a}}$ & $0.02 \pm 0.01^{b}$ & $0.01 \pm 0.00^{b}$ & $0.01 \pm 0.00^{b}$ & 0.001 & 0.005 \\
\hline Hexadecenoic acid & C16:1 & $1.73 \pm 0.45^{\mathrm{a}}$ & $0.77 \pm 0.21^{b}$ & $0.57 \pm 0.09^{b}$ & $0.51 \pm 0.05^{b}$ & 0.001 & 0.005 \\
\hline Vaccenic acid & C18:1 & $18.59 \pm 3.64^{a}$ & $16.42 \pm 1.27^{\mathrm{a}}$ & $12.47 \pm 1.14^{b}$ & $11.28 \pm 0.37^{b}$ & 0.001 & 0.183 \\
\hline Eicosenoic acid & $C 20: 1$ & $0.13 \pm 0.02^{\mathrm{a}}$ & $0.13 \pm 0.02^{\mathrm{a}}$ & $0.12 \pm 0.05^{a, b}$ & $0.11 \pm 0.03^{b}$ & 0.416 & 0.933 \\
\hline Nerve acid & C $24: 1$ & $0.36 \pm 0.08^{b}$ & $0.43 \pm 0.01^{\mathrm{a}}$ & $0.23 \pm 0.01^{c}$ & $0.23 \pm 0.01^{c}$ & 0.001 & 0.717 \\
\hline MUFA & - & $20.87 \pm 4.08^{\mathrm{a}}$ & $17.76 \pm 3.54^{\mathrm{a}, \mathrm{b}}$ & $13.41 \pm 2.23^{b}$ & $12.14 \pm 0.98^{b}$ & 0.005 & 0.217 \\
\hline Octadecadienoic acid & $\mathrm{C} 18: 2$ & $5.76 \pm 0.24^{a, b}$ & $5.28 \pm 0.06^{b}$ & $6.31 \pm 0.75^{\mathrm{a}}$ & $6.16 \pm 0.56^{a}$ & 0.344 & 0.748 \\
\hline Linolenic acid & C18:3 & $0.31 \pm 0.06^{\mathrm{a}}$ & $0.15 \pm 0.01^{b}$ & $0.20 \pm 0.01^{b}$ & $0.18 \pm 0.05^{b}$ & 0.073 & 0.005 \\
\hline Eicosadienoic acid & $\mathrm{C} 20: 2$ & $0.07 \pm 0.01^{b}$ & $0.08 \pm 0.01^{a, b}$ & $0.10 \pm 0.03^{\mathrm{a}}$ & $0.09 \pm 0.03^{a, b}$ & 0.273 & 0.294 \\
\hline Arachidonic acid & $C 20: 4$ & $0.86 \pm 0.12^{\mathrm{a}}$ & $0.96 \pm 0.01^{\mathrm{a}}$ & $0.61 \pm 0.04^{b}$ & $0.72 \pm 0.02^{b}$ & 0.003 & 0.086 \\
\hline Eicosapentaenoic acid & $C 20: 5$ & $0.01 \pm 0.00$ & $0.01 \pm 0.00$ & $0.01 \pm 0.00$ & $0.01 \pm 0.00$ & - & - \\
\hline Docosatetraenoate & $C 22: 4$ & $0.11 \pm 0.01^{\mathrm{a}}$ & $0.10 \pm 0.00^{\mathrm{a}}$ & $0.07 \pm 0.00^{b}$ & $0.07 \pm 0.01^{b}$ & 0.000 & 0.013 \\
\hline Docosapentenoic acid & $\mathrm{C} 22: 5$ & $0.07 \pm 0.01^{\mathrm{a}}$ & $0.07 \pm 0.01^{\mathrm{a}}$ & $0.07 \pm 0.01^{\mathrm{a}}$ & $0.06 \pm 0.00^{b}$ & 0.167 & 0.444 \\
\hline Docosahexenoic acid & $\mathrm{C} 22: 6$ & $0.02 \pm 0.00^{\mathrm{a}}$ & $0.02 \pm 0.01^{\mathrm{a}}$ & $0.01 \pm 0.00^{b}$ & $0.01 \pm 0.00^{b}$ & 0.019 & 0.427 \\
\hline C9-t11-CLA & - & 0.00 & $0.39 \pm 0.01^{b}$ & $1.04 \pm 0.08^{\mathrm{a}}$ & $1.55 \pm 0.11^{\mathrm{a}}$ & 0.000 & 0.003 \\
\hline t10-c12-CLA & - & 0.00 & $0.16 \pm 0.01^{b}$ & $0.54 \pm 0.01^{\mathrm{a}}$ & $0.81 \pm 0.03^{\mathrm{a}}$ & 0.000 & 0.000 \\
\hline Polyunsaturated fatty acid & - & $6.99 \pm 0.21^{b}$ & $7.22 \pm 0.23^{b}$ & $8.96 \pm 0.43^{\mathrm{a}, \mathrm{b}}$ & $9.65 \pm 0.57^{\mathrm{a}}$ & 0.000 & 0.260 \\
\hline CLA & - & 0 & $0.55 \pm 0.06^{c}$ & $1.58 \pm 0.15^{b}$ & $2.36 \pm 0.41^{\mathrm{a}}$ & 0.000 & 0.090 \\
\hline
\end{tabular}

CLA, conjugated linoleic acid; SFA, saturated fatty acid; MUFA, monounsaturated fatty acid.

1) The concentrations of C14:1, C16:1 in the egg yolk lipids were decreased linearly and quadratically, whereas C18:0, C22:4, C9-t11-CLA, t10-c12-CLA were increased linearly and quadratically; C12:0, C16:0, C17:0, C20:0, SFA, Polyunsaturated fatty acid, CLA were increased linearly; the C18:1, C24:1, MUFA, C22:4, C22:6 were decreased linearly.

a,b Values with no common superscript differ significantly $(p<0.05)$ respectively when tested with Duncan's multiple range test.

However, when the hens were fed with a diet containing $1.6 \%$ CLA, the feed consumption decreased slightly. This might be due to the negative effect of cortisol (which was significantly higher in the $1.6 \%$ group, Table 7 ) that offsets the positive effect of thyroid hormone and estradiol [24,25].

Egg quality and flavor of egg yolk
Compared with the hens given the non-CLA control diet, the eggshell of the hens fed some proportion of CLA were significantly strong. This suggests that CLA could improve concentrations of alkaline phosphatase and estradiol in laying hens, which might enhance the hydrolysis of phosphate ester bonds to release more inorganic phosphate, which in turn provides the raw material for the formation of eggshell. High levels of estradiol

Table 7. Influence of dietary CLA on serum components"

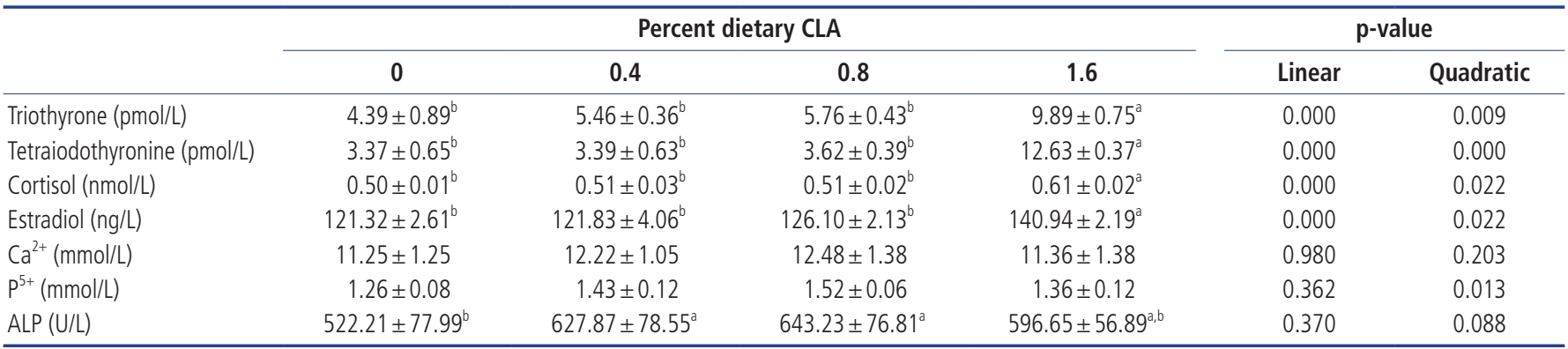

CLA, conjugated linoleic acid.

1) The concentrations of the triothyrone, tetraiodothyronine, cortisol, estradiol in the serum were increased linearly and quadratically.

a,b Values with no common superscript differ significantly $(p<0.05)$ respectively when tested with Duncan's multiple range test. 
can promote shell gland secretion and deposition, with more calcium and phosphorus, leading to increased toughness and elasticity of the eggshell [26].

The yolk color of eggs from hens fed 1.6\% CLA was significantly deepened, which might be attributed to the lipids and antioxidants in the feed, because they can improve the absorption of carotenoids and promote its deposition in the egg yolk. A study showed that CLA is a strong antioxidant [21] and may prevent carotenoids from being oxidized. Therefore, dietary supplementation with CLA can deepen the color of egg yolk.

CLA was found to affect significantly the taste and aroma of egg yolk. On one hand, it due to the change of other chemicals in egg yolk, it can be reduced from compounds such as acetaldehyde, acetone, pentane, acetic acid methyl ester, ethyl acetate, acetone, ethyl acetate, and octane $[18,19]$. On the other hand, the flavor and taste of CLA are immerged into egg yolk. The combined effect of the two factors perhaps reduces the flavor of egg yolk.

\section{Content and composition of fatty acids in egg yolk}

The present study found that, with increasing dietary CLA, SFAs, and PUFAs in egg yolk increased gradually, and unsaturated fatty acids decreased. Ahn [16] also reached the same conclusion. This shows that dietary CLA does have the physiological effect of changing the proportion of SFAs and MUFAs in egg yolk. This may be because delta-9-desaturase, a key enzyme that converts SFAs to the corresponding MUFA, is inhibited by CLA, resulting in increased SFAs and decreased MUFAs. The significant increase in PUFA in egg yolk is probably due to the inhibition of delta-6-desaturase by CLA. Belury and Kempa-Steczko [27] found that CLA is an inhibitor of delta-6-desaturase, a key enzyme that converts linolenic acid into fatty acids of C20:5 series. When delta- 6 desaturase is inhibited, hens are not able to convert C18:3 fatty acids to C20:5 fatty acids, leading to increased PUFAs in egg yolk.

Decreased linoleic acid and linolenic acid contents because of dietary CLA supplementation have been reported earlier in poultry [16], and is consistent with our conclusions of the present study. It may be attributed to lower dietary intake of linoleic acid and linolenic acid.

Arachidonic acid in egg yolk decreased after feeding with dietary CLA. This is consistent with the previous results $[19,20]$. Two mechanisms have been proposed. One is that delta- 6 desaturase, as a rate-limiting enzyme in the conversion of linoleic acid and linolenic acid to arachidonic acid, is bound competitively by CLA. The other is that linoleic and linolenic acid are higher in CLA than soybean oil, which substituted for CLA to maintain the calories supplied by each dietary regimen. As precursors of arachidonic acid, lower amounts of CLA therefore meant correspondingly lower amounts of arachidonic acid in egg yolk.

In the present study, the proportions of the CLA isomers cis-9, trans-11, and trans-10, cis-12 in the dietary supplement were very similar (39.7\% and $41.21 \%$, respectively), but in egg yolk cis- 9 , trans- 11 accounted for $66 \%$ to $70 \%$ of the total CLA, and trans-10, cis-12 isomers was $29 \%$ to $34 \%$. This suggests that these CLA isomers were differentially deposited. Raes [17] reported that the deposition efficiency of cis-9, trans-10 was higher than that of trans-11, cis-12, which is consistent with our results. However, the reasons for this selectivity remain unclear.

The overall results of this study confirm previous reports $[8,9,17,18,22]$ that increasing CLA in the diet of laying hens increases the concentrations of CLA, SFAs, and PUFAs, and decreases the concentrations of MUFAs in egg yolk. Dietary CLA was found to enhance significantly the eggshell toughness. The incorporation of CLA isomers into egg yolk lipids implies that CLA supplementation could add to the value of chicken eggs for human consumption. However, the adverse effects of dietary CLA on egg quality (such as the odor, flavor, taste) need to be prevented.

\section{CONFLICT OF INTEREST}

We certify that there is no conflict of interest with any financial organization regarding the material discussed in the manuscript.

\section{ACKNOWLEDGMENTS}

This work was supported by a grant (ZR2015YL062) of Natural Foundation of Shandong Province.

\section{REFERENCES}

1.Shen AZ. Study on medication compliance of patients with hypertension, diabetes and coronary heart disease. Anhui China: Medical University Of Anhui; 2005.

2.Li R, Yang QD, Li YY, Shi L, Ruan Y. Current status and progress of diabetes prevention and treatment in community of Shanghai. China Public Health Management 2010;5:126-8.

3.Ha YL, Grimm NK, Pariza MW. Anticarcinogens from fried ground beef: heat-altered derivatives of linoleic acid. Carcinogenesis 1987; 8:1881-7.

4.Chin SF, Liu W, Storkson JM, Ha YL, Pariza MW. Dietary sources of conjugated dienoic isomers of linoleic acid, a newly recognized class of anticarcinogens. J Food Compost Anal 1992;5:185-97.

5.Lee KN, Kritchevsky D, Pariza MW. Conjugated linoleic acid and atherosclerosis in rabbits. Atherosclerosis 1994;108:19-25.

6.Nicolosi RJ, Rogers EJ, Kritchevsky D, Scimeca JA, Huth PJ. Dietary conjugated linoleic acid reduces plasma lipoproteins and early aortic atherosclerosis in hypercholesterolemic hamsters. Artery 1997;22: 266-77.

7.Du M, Ahn DU. Effect of dietary conjugated linoleic acid on the growth rate of live birds and on the abdominal fat content and quality of broiler meat. Poult Sci 2002;81:428-33. 
8.Szymczyk B, Pisulewski PM. Effects of dietary conjugated linoleic acid on fatty acid composition and cholesterol content of hen egg yolks. Br J Nutr 2003;90:93-9.

9.Jones S, Ma DW, Robinson FE, Field CJ, Clandinin MT. Isomers of conjugated linoleic acid (CLA) are incorporated into egg yolk lipids by CLA-fed laying hens. J Nutr 2000;130:2002-5.

10. Zhang H, Guo Y, Yuan J. Conjugated linoleic acid enhanced the immune function in broiler chicks. Br J Nutr 2005;94:746-52.

11. Takahashi K, Akiba Y, Iwata T, Kasai M. Effect of a mixture of conjugated linoleic acid isomers on growth performance and antibody production in broiler chicks. Br J Nutr 2003;89:691-4.

12. Ostrowska E, Muralitharan M, Cross RF, Bauman DE, Dunshea FR. Dietary conjugated linoleic acids increase lean tissue and decrease fat deposition in growing pigs. J Nutr 1999;129:2037-42.

13. Thiel-Cooper RL, Parrish FC, Jr., Sparks JC, Wiegand BR, Ewan RC. Conjugated linoleic acid changes swine performance and carcass composition. J Anim Sci 2001;79:1821-8.

14. Wiegand BR, Sparks JC, Parrish FC, Jr., Zimmerman DR. Duration of feeding conjugated linoleic acid influences growth performance, carcass traits, and meat quality of finishing barrows. J Anim Sci 2002;80:637-43.

15. Tischendorf F, Schone F, Kirchheim U, Jahreis G. Influence of a conjugated linoleic acid mixture on growth, organ weights, carcass traits and meat quality in growing pigs. J Anim Physiol Anim Nutr (Berl) 2002;86:117-28.

16. Ahn DU, Sell JL, Jo C, Chamruspollert M, Jeffrey M. Effect of dietary conjugated linoleic acid on the quality characteristics of chicken eggs during refrigerated storage. Poult Sci 1999;78:922-8.

17. Raes K, Huyghebaert G, De Smet S, et al. The deposition of conjugated linoleic acids in eggs of laying hens fed diets varying in fat level and fatty acid profile. J Nutr 2002;132:182-9.

18. Shang XG, Wang FL, Li DF, Yin JD, Li JY. Effects of dietary conjugated linoleic acid on the productivity of laying hens and egg quality during refrigerated storage. Poult Sci 2004;83:1688-95.

19. Cherian G, Goeger MP, Ahn DU. Dietary conjugated linoleic acid with fish oil alters yolk n-3 and trans fatty acid content and volatile compounds in raw, cooked, and irradiated eggs. Poult Sci 2002;81: 1571-7.

20 Schafer K, Manner K, Sagredos A, Eder K, Simon O. Incorporation of dietary linoleic and conjugated linoleic acids and related effects on eggs of laying hens. Lipids 2001;36:1217-22.

21. Chamruspollert M, Sell JL. Transfer of dietary conjugated linoleic acid to egg yolks of chickens. Poult Sci 1999;78:1138-50.

22. Watkins BA, Feng S, Strom AK, et al. Conjugated linoleic acids alter the fatty acid composition and physical properties of egg yolk and albumen. J Agric Food Chem 2003;51:6870-6.

23. Zhu XJ. Effects of soybean isoflavone and F89 analogues on the feeding and laying performance of laying hens and endocrine mechanism. Nanjing, China: Nanjing Agricultural University; 2003.

24. Liu XL. Dietary conjugated linoleic acid level affects performance, eggshell quality and serum biochemical indices of laying hens. Chinese J Anim Nutr 2012.

25. Li XX, Jin MM, Tian YD, Kang XT. Effects of Dietary Conjugated Linoleic Acid on Egg Quality and Serum Biochemical Indexes of Gushi Layers. J Henan Agric Sci 2009;7:124-6.

26. Liu P, Jiang CDX. Effect of chromium on production performance of laying hens and the distribution of in vivo. J Jiangxi Agric Univ 1999;21:564-8.

27. Belury MA, Kempa-Steczko A. Conjugated linoleic acid modulates hepatic lipid composition in mice. Lipids 1997;32:199-204. 